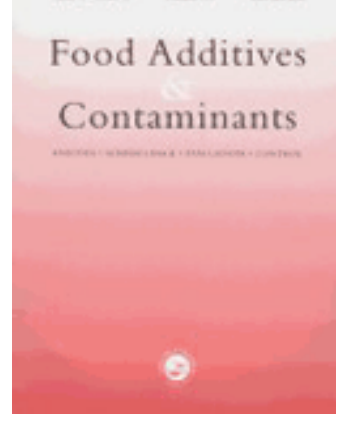

\title{
Determination of acrylamide in coffee and coffee products by GC-MS using an improved SPE clean-up
}

\begin{tabular}{|r|l|}
\hline Journal: & Food Additives and Contaminants \\
\hline Manuscript ID: & TFAC-2006-141.R1 \\
\hline Manuscript Type: & Original Research Paper \\
\hline $\begin{array}{r}\text { Date Submitted by the } \\
\text { Author: }\end{array}$ & 22-Jun-2006 \\
\hline Complete List of Authors: & $\begin{array}{l}\text { Dias Soares, Cristina; FFUP, Food Science } \\
\text { Cunha, Sara; FFUP, Food Science } \\
\text { Fernandes, José; FFUP, Food Science }\end{array}$ \\
\hline Methods/Techniques: & Chromatography - GC/MS, Clean-up, Extraction, GC/MS \\
\hline Additives/Contaminants: & Acrylamide, Process contaminants - acrylamide \\
\hline Food Types: & Coffee, Processed foods \\
\hline & \\
\hline $\begin{array}{l}\text { Note: The following files were submitted by the author for peer review, but cannot be converted } \\
\text { to PDF. You must view these files (e.g. movies) online. }\end{array}$ \\
\hline \begin{tabular}{l} 
Table I.doc \\
\hline
\end{tabular}
\end{tabular}

\section{SCHOLARONE" Manuscripts}




\section{Determination of acrylamide in coffee and coffee products by GC-MS}

2 using an improved SPE clean-up

3

4 Cristina Soares, Sara Cunha, and José Fernandes

5

6 FFUP Food Science, Rua Aníbal Cunha, 164 Porto 4050-047 (Portugal)

\section{Abstract}

9

10 An improved GC-MS method to determine acrylamide (AA) in coffee and coffee

11 products was developed. The method was based in two main purification steps, the first

12 one with ethanol and Carrez solutions in order to precipitate polysaccharides and

13 proteins, respectively, and the second with a layered solid phase extraction (SPE)

14 column which proved to be efficient to eliminate the main chromatographic

15 interferences. The method is applicable to a wide range of coffee products. Twenty six

16 samples of different coffee products were analysed. The levels of AA were in the range

17 of $11.4-36.2 \mu \mathrm{g} \mathrm{L}^{-1}$ for "espresso coffee" and $200.8-229.4 \mu \mathrm{g} \mathrm{L} \mathrm{L}^{-1}$ for coffee blends

18 with cereals. The results indicated that the presence of cereals significantly increased

19 the levels of AA.

20

21 Keywords: Coffee, SPE clean up, acrylamide, GC-MS

24 Introduction 
25 The occurrence of acrylamide (AA) in foodstuffs particularly in certain baked and fried 26 products such as potato chips and French fries was first reported by Tareke et al. (2002).

27 AA is now known to be formed by the Maillard reaction during industrial food 28 processing, retail, catering and home food preparation ((Mottram et al., 2002; Stadler et 29 al., 2002; Becalski et al., 2003).. The foodstuffs that contribute most to AA exposure 30 vary depending upon the population's nutritional habits and the way the food is 31 prepared and processed (Dybing et al., 2005). Generally, the most important sources of 32 AA appear to be potato products (potato chips, French fries, and potato snacks), cereals 33 (breakfast cereals, roasted cereals), baked goods (bread, cookies, biscuits), and brewed 34 coffee.

Recent reports showed that coffee is among the highest contributors to the AA intake in 37 some countries in Europe. In Sweden the main dietary intake of AA from coffee was estimated to be $12 \mu \mathrm{g} /$ day, representing $\sim 39 \%$ of the total dietary intake of $31 \mu \mathrm{g} /$ day 39 (Svensson et al., 2003). These results were based on ready-to-drink coffee samples that 40 contained around $25 \mu \mathrm{g} \mathrm{kg}^{-1}$ AA. Dybing and Sanner (2003) reported that a mean intake 41 of AA from coffee was estimated to contribute to $28 \%$ of the $38 \mu \mathrm{g} / \mathrm{day}$ for males and $29 \%$ of the $29 \mu \mathrm{g} /$ day for females in Norway. Their results were based on a study

43 (Norwegian Food Control Authority, 2002) that reported concentrations of AA in filter 44 coffee of $25 \mu \mathrm{g} \mathrm{kg}^{-1}$ and $10 \mu \mathrm{g} \mathrm{kg}^{-1}$ in instant coffee. A Swiss total diet study of AA in 45 the diet of 14 men and 13 women showed that coffee contributed $36 \%$ of the total intake 46 (Brunner et al., 2002). Granby and Fagt (2004) found in their study 2-16 $\mu \mathrm{g} \mathrm{L}^{-1}$ of AA 47 in brewed coffee and $10 \mu \mathrm{g} \mathrm{L}^{-1} \mathrm{AA}$ in instant coffee. They concluded that the AA intake 48 from coffee consumption in Denmark was $10 \mu \mathrm{g} /$ day for males and $9 \mu \mathrm{g} /$ day for 
49 females. Assuming that the total exposure of Danish consumers is comparable to those 50 of Sweden and Norway, the mean exposure to AA from coffee contributes to $20 \%$ of 51 the total AA exposure. In Netherlands, Boon et al. (2005) accounted an AA 52 concentration in coffee in the range $4-45 \mu \mathrm{g} \mathrm{kg}^{-1}$ that contributes with $13 \%$ of the total 53 AA intake in adults. The US Food and Drug Administration (FDA) reported levels of 54 AA in brewed coffee ranging from 6 to $16 \mu \mathrm{g} \mathrm{L}^{-1}$ (Andrzejewski et al., 2004).

In Portugal, coffee is highly consumed as "espresso" which has a peculiar brewing 57 technique: a small amount of hot water $( \pm 30 \mathrm{~mL})$ is percolated in a very short time at 58 high pressure through a layer of ground roasted coffee $( \pm 6-7 \mathrm{~g})$, the coffee cake, to 59 produce efficiently a very concentrated brew $(\approx 200 \mathrm{~g}$ of ground coffee per litre $)$ 60 comparing with the $20-60 \mathrm{~g}$ of ground coffee per litre related in the above mentioned countries (Nunes \& Coimbra, 1987).

62

Several methods to determine AA in food have been developed and they are based on

64 either GC-MS with derivatisation with bromine (Andrawes et al., 1987; Nemoto et al.,

65 2002; Ono et al., 2003; Pittet et al., 2004) and without derivatisation (Jezussek \& Schieberle, 2003; Biedermann et al., 2002; Amrein et al., 2005) or LC-MS with

67 derivatisation with mercaptobenzoic acid (Jezussek \& Schieberle, 2003) and without derivatisation (Roach et al, 2003; Becalski et al., 2003; Ahn et al., 2002; Rosén et al., 69 2002; Şenyuva \& Gökmen, 2005 \& 2006; Delatour et al., 2004; Andrzejewski et al., 70 2004; Yusà et al., 2006). Independently of the chromatographic technique adopted, the success of the methods is very dependent of the extraction and clean-up steps. The most used procedures usually fail when dealing with coffee products, due to their inability to 
73 avoid the presence of interferences that co-elute with the analyte thus preventing its 74 correct quantification (Delatour et al., 2004).

76 The methods developed so far to determine AA in coffee and coffee products, are based 77 mainly in LC-MS/MS with variations in the clean-up conditions employed. Roach et al. 78 (2003) used a combination of Oasis HLB and Bond Elut-Accucat SPE cartridges before 79 the LC analysis but found coffee to be a troublesome matrix. The method still presents 80 some problems regarding contaminations, as it requires frequently reconditioning the 81 HPLC column (Andrzejewski et al., 2004). Granby and Fagt (2004) performed a single82 step clean-up on $300 \mathrm{mg}$ Isolute Multimode SPE columns of five hundreds microlitres 83 of sample to make the clean-up more efficient and eliminate almost completely the 84 colour from the coffee. However, they referred that the loading of the SPE cartridge with the sample exceeding $0.5 \mathrm{~mL}$ resulted in a suppression of the MS response.

86 Şenyuva and Gökmen (2005) extracted AA from ground coffee using methanol instead 87 of water and the clean-up was made with Oasis HLB SPE cartridges prior to LC 88 analysis. Delatour et al. (2004) used $500 \mathrm{mg}$ of Isolute Multimode SPE cartridges to 89 clean-up $2 \mathrm{~mL}$ of samples but realized that a single step was not effective and developed 90 a combination of liquid-liquid and solid phase extraction methods. Ono et al. (2003)

91 determined acrylamide in several food items including roasted coffee by GC-MS.

92 However no reference was made about the efficiency of their method to coffee analysis.

93 The set of methods developed so far demonstrate a lack in the methodologies employing

94 GC-MS with the objective to specifically determine AA in coffee samples. 
96 The objective of this work was to develop a method to determine AA in several coffee

97 products using GC-MS as analytical technique. The method was successfully applied to determine acrylamide in ready-to-drink products and ground coffee, that was analysed

99 as "espresso".

100

$101 \quad$ Experimental

102

Sampling and coffee preparation

103 Eighteen samples of roasted coffee beans, five samples of instant coffee, two of them

104 decaffeinated, two samples of coffee blends with cereals and one soluble "cappuccino"

105 were collected from several supermarkets and stored at room temperature. The most

106 common brands were selected. The roasted coffee beans were ground in a coffee grinder 107 incorporated in a Philips coffee machine, model Espresso Professional selected for a

108 fine grain size typical for espresso coffee preparation. Each espresso was prepared in

109 duplicate according to the typical conditions used in Portugal for an "espresso" 110 preparation, i.e.: $7 \mathrm{~g}$ of ground coffee extracted with hot water during $30 \pm 5 \mathrm{~s}$ (about 30

111 to $35 \mathrm{~mL}$ of water) at an inlet pressure of $9 \pm 2$ bar. Two grams of instant coffee, coffee

112 blends and cappuccino were dissolved in $10 \mathrm{~mL}$ of deionised water.

\section{Chemicals}

115 Acrylamide (AA) 99\% purity grade was acquired from Aldrich (Steinheim, Germany). 116 Acrylamide 1,2,3-C13 $\left({ }^{13} \mathrm{C}_{3}\right.$-AA) $99 \%$ in methanol was purchased from Cambridge 117 Isotope Laboratories (Andover, MA, USA). The solid-phase extraction (SPE) columns, 118 Isolute Multimode, $3 \mathrm{~g}$ custom made, were from International Sorbent Technology 119 (Hengoed, Mid Glamorgan, UK). The preparative $\mathrm{C}_{18}$ sorbent $125 \AA$ А, 55-105 $\mu \mathrm{m}$ was 
120 from Waters (Milford, USA). The filters were polyethylene single fritted reservoir 25

$121 \mathrm{~mL}$, filter pore size $10 \mu \mathrm{m}$ (Symta, Madrid, Spain). The $\mathrm{n}$-hexane and ethyl-acetate were

122 of pesticide residue analysis grade and methanol and acetonitrile were of ultrapure

123 grade, all from Fluka. The potassium bromide for IR spectroscopy grade and the

124 bromine analytical grade were from Merck (Darmstad, Germany). Sodium chloride

125 analytical grade was from J.T. Baker (Deventer, Holland). Potassium hexacyanoferrate

126 (II) trihydrate, zinc sulphate heptahydrate, acetic acid (glacial) and absolute ethanol

127 were analytical grade obtained from Panreac (Barcelone, Spain). Hydrobromic acid

$12848 \%$ and sodium tiosulphate volumetric solution $1 \mathrm{~mol} \mathrm{~L}^{-1}$ were from Riedel-de Häen

129 (Seelze, Germany).

130

$131 \quad$ Standards and reagents

132 A stock solution of $\mathrm{AA}\left(2 \mathrm{~g} \mathrm{~L}^{-1}\right)$ was prepared by dissolving the compound in

133 acetonitrile, and appropriately diluted to prepare a working standard solution at $4 \mathrm{mg} \mathrm{L}^{-}$

134 . A stock solution of internal standard, ${ }^{13} \mathrm{C}_{3}$-AA, was prepared by the same way with

135 the difference that the working standard solution was made at $40 \mathrm{mg} \mathrm{L}^{-1}$. All stock and

136 working solutions were stored at $4^{\circ} \mathrm{C}$. Saturated bromine water solution and Carrez

137 reagents were prepared according to Pittet et al. (2004).

139 Sample preparation

140 To $10 \mathrm{~mL}$ of "espresso" coffee or $2 \mathrm{~g}$ of other coffee product dissolved in $10 \mathrm{~mL}$ of

141 water, $15 \mathrm{~mL}$ of absolute ethanol were added and the solution shaken for $\sim 1 \mathrm{~min} .0 .5$

$142 \mu \mathrm{g}$ of IS was added and the solution was shaken again and then kept at $-20^{\circ} \mathrm{C}$ during 15

143 minutes. It was centrifuged at $15000 \mathrm{~g}\left(5\right.$ minutes, $\left.4^{\circ} \mathrm{C}\right)$ and the resulting solution was 
144 transferred to a centrifugal flask. Afterwards, it was acidified with acetic acid until pH 145 4-5 (0.1-0.2 mL). $1 \mathrm{~mL}$ of Carrez I and $1 \mathrm{~mL}$ of Carrez II solutions were added and then 146 the flask shaken and kept at $4{ }^{\circ} \mathrm{C}$ for 15 minutes. The solution was centrifuged at 15000 $147 \mathrm{~g}\left(15\right.$ minutes, $\left.4^{\circ} \mathrm{C}\right)$ and filtrated to a $40 \mathrm{~mL}$ vial through the polyethylene filters. The 148 volume of the solution was reduced to $2-3 \mathrm{~mL}$ in a rotary evaporator at $55^{\circ} \mathrm{C}$ and 149 transferred to a $20 \mathrm{~mL}$ vial. The rotary evaporator vessel was washed with $2 \mathrm{~mL}$ of 150 water that was added to the solution in the vial. If necessary a centrifugation at $3000 \mathrm{~g}$ 151 was performed to deposit suspended solids in the solution prior to the SPE clean-up.

153 SPE clean-up

154 The SPE columns were prepared by adding a 1g layer of C18 sorbent to the Isolute 155 Multimode $3 \mathrm{~g}$ column. This layer was covered with a polyethylene frit (pore size 10 $156 \mu \mathrm{m})$. The columns were conditioned first with $20 \mathrm{~mL}$ of methanol and then with $20 \mathrm{~mL}$ 157 of water. The sample solution $(\sim 5 \mathrm{~mL})$ was loaded on the column and the first $2 \mathrm{~mL}$ of 158 the eluate were discarded. The remaining solution $(\sim 3 \mathrm{~mL})$ was collected in a $40 \mathrm{~mL}$ 159 vial and the column was washed with $10 \mathrm{~mL}$ of water that was collected to the same 160 vial.

161

162 For instant coffee it was necessary to perform a previous SPE cleaning with a $3 \mathrm{~g} \mathrm{C18}$ 163 columns home made prior to the Isolute cleaning. The column was conditioned under 164 the same conditions as the Isolute column and the sample was loaded and eluted with 165 just $1 \mathrm{~mL}$ of water. This solution was collected and loaded in the prepared Isolute 166 columns. 
168

169 To the collected extract $1 \mathrm{~g}$ of calcinated $\mathrm{KBr}$ was added. The solution was then

170 acidified with $\mathrm{HBr}$ until $\mathrm{pH} \mathrm{1-3} \mathrm{(100-150} \mu \mathrm{L})$ and $2 \mathrm{~mL}$ of saturated bromine solution

171 were added. The solution was allowed to stand in an ice bath and kept from the light at

172 least during $1 \mathrm{~h}$. The excess bromine in the solution was decomposed by the addition of

$1731 \mathrm{~mol} \mathrm{~L}^{-1}$ sodium tiossulphate until the yellow colour disappeared $(50-150 \mu \mathrm{L})$. The

176

178

179

180

181

182

183

184

185

186

187

188 Equipment

189 GC-MS analysis were performed in a gas-chromatograph, model HP GC-6890, split-

190 splitless injector, coupled to a Mass Selective Detector model Agilent MSD-5973N

191 (Agilent, Palo Alto, CA, USA). The analytical separation was performed in a capillary 
192 column DB 1301 (30 m x $0.25 \mu \mathrm{m}, 0.25 \mathrm{~mm}$ i.d.) from J\&W Scientific (Folsom, CA,

193 USA). The centrifugations were made in an ultra-centrifuge from Eppendorf, model

1945810 R (Hamburg, Germany) at $15000 \mathrm{~g}$ and in a Heraeus Sepatek, model Labofuge Ae

195 (Osterode, Germany) at 3000 g. The SPE clean-up was made in a Visiprep Solid Phase

196 Extraction Manifold from Supelco (Taufkirchen, Germany) with capacity for 12

197 columns. Evaporation of the solvents was performed in a Büchi Rotavapor model RE

198111 and 461 water bath (Flawil, Switzerland). The evaporation under a stream of

199 nitrogen was carried out on a Pierce, model Reacti-therm 18790 (Rockford, IL, USA)

200 with capacity for 9 vials.

201

202 GC-MS Operating conditions

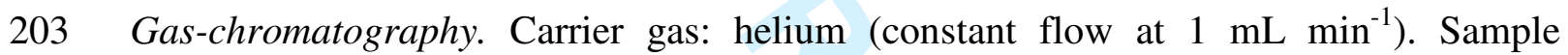
204 injection volume: $1 \mu \mathrm{L}$ (splitless, pulsed pressure $32 \mathrm{psi}, 60 \mathrm{sec}$ ). Injector temperature: $205280^{\circ} \mathrm{C}$. Oven temperature: $85^{\circ} \mathrm{C}(1 \mathrm{~min}), 15^{\circ} \mathrm{C} \min ^{-1}$ to $280^{\circ} \mathrm{C}$, hold $10 \min (24 \mathrm{~min})$, 206 transfer line, $240^{\circ} \mathrm{C}$.

207 Mass-spectrometry. Electron energy, $70 \mathrm{eV}$ (EI mode). Mode of acquisition: selected 208 ion monitoring (SIM), $m / z, 106,108,150$ and 152 for 2,3-dibromopropionamide (2,3209 DBPA) and $m / z, 110,153,155$ for $2,3-{ }^{13} \mathrm{C}_{3}$ - dibromopropionamide $\left(2,3-{ }^{13} \mathrm{C}_{3}\right.$-DBPA).

210 The ions $m / z \quad 150$ for 2,3-DBPA, $m / z \quad 155$ for 2,3-DBPA $\left({ }^{13} \mathrm{C}_{3}\right)$ were used for 211 quantification and the others for confirmation. AA was determined with the internal 212 standard using the ratio of peak area of 2,3 -DBPA to $2,3-{ }^{13} \mathrm{C}_{3}$-DBPA. The identity of 213 the peak was confirmed by retention time and by comparing the relative abundance 214 ratios of the confirmatory ions with those of standard solution. 


\section{Results and discussion}

217 Method development

218 Aiming for screening of the presence of AA in food products largely consumed in 219 Portugal, we developed a GC-MS methodology (not published) based on the several 220 papers published in this field (Tareke et al, 2002; Nemoto et al., 2002; Ono et al., 2003; 221 Pittet et al., 2004; Biedermann et al., 2002; Delatour et al., 2004). Briefly, AA was 222 extracted from the samples with water at $65^{\circ} \mathrm{C}$, Carrez solutions were added in order to 223 precipitate proteins, the upper layer partially evaporated and finally the compound was 224 brominated, extracted twice by ethyl acetate:n-hexane 4:1 (v/v) and then analysed by 225 GC-MS in SIM mode.

226

227 As reported by other authors (Delatour et al., 2004; Andrzejewski et al., 2004) that used 228 similar methods, some drawback occurred when difficult matrices were analysed, 229 namely coffee products. Taking this into account some modifications were introduced 230 in our previous developed method.

232 The addition of absolute ethanol to coffee samples intended to control the great quantity 233 of foam that was constantly being formed during almost all steps of the sample 234 preparation and resulting in severe losses of the analyte and contamination of the used 235 instruments. The problem was particularly serious during the evaporation step on the 236 rotary evaporator because the foam was always being projected. The adopted solution 237 was an adaptation from the work of Nunes and Coimbra (1998), where the precipitation 238 of polymeric polysaccharides, responsible for the "foam stability" in espresso coffees, 239 was achieved by adding 55 and $75 \%$ ethanol solution at $4{ }^{\circ} \mathrm{C}$ during one hour. After 
240 trials with $5,10,15,20,25 \mathrm{~mL}$ of ethanol, $15 \mathrm{~mL}$ were found to give the best results.

241 The precipitation time was decreased to 15 minutes by changing the precipitation 242 temperature from $4^{\circ} \mathrm{C}$ to $-20^{\circ} \mathrm{C}$.

244 The SPE clean-up was a challenge in the sense that it was difficult to achieve the correct 245 ratio between the two used sorbents. The use of a single purification step with $\mathrm{C}_{18}$ 246 revealed to be useful to eliminate the coffee colour but it was not effective to remove 247 other compounds that overlapped the 2,3-DBPA peak no matter what quantity of 248 sorbent was used. When using Isolute Multimode cartridges ( 0.5 or $1 \mathrm{~g})$ it was verified 249 that the sorbent layer was completely saturated with very small quantities of coffee 250 samples $(0.5-1.0 \mathrm{ml})$. Because it was difficult to achieve such small sample volumes 251 during the evaporation step, the rejection of an important portion of the extract was 252 necessary, with the inherent loss of sensitivity of the overall method. The solution found 253 was to increase the quantity of sorbent material instead of decreasing the sample 254 volume. The use of higher quantities of Isolute Multimode (3g) resulted in an increase 255 of the analytical signal but it was not effective to eliminate the coloured compounds and 256 suppression of the MS response was observed. The addition of both sorbents in a single

257 step was the solution found to surpass both problems. It was found that a ratio of 1:3 of $258 \mathrm{C}_{18}$ : Isolute was ideal to eliminate the most relevant contaminants present in "espresso" 259 coffee.

261 Soluble coffees, revealed to be a troublesome matrix due to its high percentage of 262 concentrated polysaccharides. The addition of ethanol was not enough to eliminate the 263 majority of the polysaccharides that increased the formation of foam and the 1:3 ratio 
264 between the sorbents was incapable of eliminate all the interferences observed in the 265 analytical signal. Besides, these samples provoked contamination of the injector, what 266 demanded constant changing of the liner sometimes just after few injections. The 267 addition of a bigger top layer of $\mathrm{C}_{18}$ was impracticable due to the dimensions of the 268 used cartridges. The use of a previous clean-up step with a $\mathrm{C}_{18}$ sorbent, in which the 269 majority of the coloured compounds were eliminated, followed by a second clean-up 270 step with the " $\mathrm{C}_{18}$ layered" Isolute column was the best solution found. Notwithstanding 271 the slight decrease observed in the analytical signal, the use of a "clean" extract 272 provided a much better quality of the chromatographic results.

274 The analytical separation of acrylamide was performed in a DB 1301 capillary column. 275 In Figure 1 is presented a chromatogram for an "espresso" coffee sample with $20,8 \mu \mathrm{g}$ $\mathrm{L}^{-1} \mathrm{AA}$ and $0.5 \mu \mathrm{g}{ }^{13} \mathrm{C}_{3}$-AA corresponding $50 \mu \mathrm{g} \mathrm{L}{ }^{-1}$ in the sample.

Method assessment

282 Linearity. The linearity of the method was tested several times using standard 283 (calibrating) solutions performed in water and treated using the same method developed 284 for the samples. Six standards were simultaneously prepared and treated in parallel with 285 the sample. The range of concentrations varied according to the expected levels of AA 286 in coffee samples. Typical ranges were $0-300 \mu \mathrm{g} \mathrm{L}^{-1} \mathrm{AA}$ in the sample. The quantity of 287 IS was $0.5 \mu \mathrm{g}$ corresponding to $50 \mu \mathrm{g} \mathrm{L}^{-1}$ in the sample for all samples and standards. 
288 Calibration curves were constructed by plotting the AA/IS area ratio against the 289 concentration of AA in the standard. The correlation coefficients were usually higher then 0.997 .

292 Precision. To study the precision of the method, an "espresso" coffee $(\sim 30 \mathrm{~mL})$ was 293 divided in three aliquots of $10 \mathrm{~mL}$ each, which were submitted to the overall developed 294 method and injected twice. The RSD obtained was $6.3 \%$.

296 Recovery. For the recovery test, an instant coffee surrogate solution (containing 200.8 $297 \mu \mathrm{g} \mathrm{L}^{-1}$ of AA) was prepared with $8 \mathrm{~g}$ of powder dissolved in $40 \mathrm{ml}$ of water and divided 298 into four aliquots of $10 \mathrm{ml}$ each. AA was added at each aliquot at the levels from 0 to 2 $299 \mu \mathrm{g}$ corresponding to $0-200 \mu \mathrm{g} \mathrm{L}^{-1}$. After addition of IS the samples were analysed by 300 the described overall method. The AA recovery from the spiked solutions varied 301 between 97.4 to $108.4 \%$.

303 Limit of detection and limit of quantification

304 No exhaustive studies for determining the limit of detection were made. However, 305 standards containing $10 \mu \mathrm{g} \mathrm{L}^{-1}$ of $\mathrm{AA}$, were used to construct the calibration curves. 306 Under conditions of ideal performance of the MS detector, it was possible to integrate 307 the corresponding peaks of AA and for the IS. Replicate analysis (extraction procedure 308 included) of these standards showed that the values obtained for the ratio area of AA/IS, 309 presented a R.S.D. less than $15 \%$. This fact was confirmed when samples containing 310 very low levels of AA were analysed. For example, a sample of Espresso coffee 311 containing $20.5 \mu \mathrm{g} \mathrm{L}^{-1}$ of AA was analysed in triplicate ant the RSD obtained was 13.6 
$312 \%$. Below this level of concentration the values obtained registered an R.S.D. above $31315 \%$.

314

\section{Method application}

316 The method developed was applied to 26 coffee samples (roasted beans, instant and

317 coffee blends). Samples were randomly selected from supermarkets, and therefore may

318 not be representative of coffee supply. Nevertheless they represent a general guide to

319 AA concentration in a selected segment of coffee supply. The results obtained are 320 presented in Table I. Accordingly AA levels ranged from 11.4 to $36.2 \mu \mathrm{g} \mathrm{L}^{-1}$ in ground 321 roasted coffee analysed as "espresso", 47.4 to $95.2 \mu \mathrm{g} \mathrm{L}^{-1}$ for instant coffee and 200.8 to $322229.4 \mu \mathrm{g} \mathrm{L}^{-1}$ for coffee blends with cereals. Soluble "cappuccino" contained $6.4 \mu \mathrm{g} \mathrm{L}$.

323 Considering that $6 \mathrm{~g}$ of ground coffee extracted with $\sim 30 \mathrm{~mL}$ water are used to prepare 324 an "espresso", the concentration of AA per cup is therefore 0.32 to $1.46 \mu \mathrm{g} / 30 \mathrm{~mL}$. To 325 prepare a cup of instant coffee the usual measure is $2 \mathrm{~g}$ per individual portion making 3260.47 to $0.95 \mu \mathrm{g}$ per $30 \mathrm{~mL}$. Considering that coffee blends with cereals were prepared as 327 soluble coffee ( $2 \mathrm{~g} / 30 \mathrm{~mL}$ cup) the concentration of AA per cup is therefore 2.01 to $3282.09 \mu \mathrm{g}$ per $30 \mathrm{~mL}$ cup. "Cappuccino" as analysed is a soluble mixture of coffee, milk 329 powder, cocoa and sugar and each individual dose correspond to $14 \mathrm{~g}$, resulting in an 330 AA concentration of $0.45 \mu \mathrm{g}$ per $30 \mathrm{~mL}$ cup. These results highlight the fact that the 331 addition of cereal products to coffee increased the amount of AA. This in agreement 332 with studies (Yusà et al., 2006) reporting that cereal products form substantial amounts 333 of AA due to their chemical constitution and processing.

335 [Insert Table I about here] 


\section{Conclusion}

338 To date, LC/MS has been the most widely used analytical approach to assay AA in 339 coffee. GC/MS methods usually suffer from the presence of co-extractives which

340 rapidly contaminate the chromatographic system, degrading the respective performance

341 and avoiding the correct quantification of AA. This paper describes a GC/MS method

342 based on an improved sample preparation procedure that enables the correct

343 quantification of AA in coffee extracts without the problems generally associated with

344 those kind of samples. The high levels of sensitivity, and reproducibility achieved

345 recommend it when dealing with this type of food matrices. The method was applied to

346 several coffee products and the quantity of AA was found to be dependent on the coffee

347 processing and preparation, namely the addition of cereals.

\section{Acknowledgements}

350 The authors are thankful to FCT for financial support in the framework of the project 351 POCI/AGR/61543/2004.

\section{References}

Ahn JS, Castle L, Clarke DB, Lloyd AS, Philo MR, Speck DR. 2002.Verification of the findings of acrylamide in heated foods. Food Additives and Contaminants 19:11161124.

357 Amrein TM, Lukac H, Andres L, Perren R, Escher F, Amado R. 2005. Acrylamide in 358 Roasted Almonds and Hazelnuts. Journal of Agricultural and Food Chemistry 359 53:7819-7825. 
360 Andrawes F, Greenhouse S, Draney D. 1987. Chemistry of acrylamide bromination for 361 trace analysis by Gas Chromatography and Gas Chromatography-Mass 362 Spectrometry. Journal of Chromatography 399:269-275.

363 Andrzejewski D, Roach JA, Gay ML, Musser SM. 2004. Analysis of Coffee for the 364 presence of Acrylamide by LC-MS/MS. Journal of Agricultural of Food Chemistry $365 \quad 52: 1996-2002$.

366 Becalski A, Lau BP, Lewis D, Seaman SW. 2003. Acrylamide in Foods: Occurrence, 367 Sources, and Modeling. Journal of Agricultural and Food Chemistry 51:802-808.

368 Biedermann M, Biedermann-Brem S, Noti A, Grob K, Egli P, Mändli H. 2002. Two 369 GC-MS Methods for the Analysis of Acrylamide in Foodstuffs. Mitteilungen aus 370 Lebensmitteluntersuchung und Hygiene 93:638-652.

371 Boon PE, de Mul A, van der Voet H, van Donkersgoed G, Brette M, van Klaveren JD. 372 2005. Calculations of dietary exposure to acrylamide. Mutation Research 580:143$373 \quad 155$.

374 Brunner K, Dudler V,Reinhard H, Rhyn P, Rupp H, Sager F, Streule M, Zimmermann 375 H. and. Zoller O. 2002. Assessment of acrylamide intake by duplicate diet study. 376 Swiss Federal Office of Public Health, Bern. Available from: 377 http://www.bfr.bund.de/cm/208/assessment_of_acrylamide_intake_by_duplicate_di 378 et_study.pdf. Accessed 2006 March 15.

379 Delatour T, Perisset A, Goldmann T, Riediker S, Stadler RH. 2004. Improved Sample 380 Preparation to Determine Acrylamide in Difficult Matrixes Such as Chocolate 381 Powder, Cocoa, and Coffee by Liquid Chromatography Tandem Mass 382 Spectrometry. Journal of Agricultural and Food Chemistry 52:4625-4631. 
383 Dybing E, Farmer PB, Andersen M, Fennell TR, Lalljie SPD, Müller DJG, Olin S, 384 Petersen BJ, Schlatter J, Scholz G, Scimeca JA, Slimani N, Törnqvist M, Tuijtelaars

385 S, Verger P. 2005. Human exposure and internal dose assessments of acrylamide in 386 food. Food and Chemical Toxicology 43:365-410.

387 Dybing E, Sanner T. 2003. Risk assessment of acrylamide in foods. Toxicological $388 \quad$ Sciences 75:7-15.

389 Granby K, Fagt S. 2004. Analysis of acrylamide in coffee and dietary exposure to 390 acrylamide from coffee. Analytica Chimica Acta 520:177-182.

391 Jezussek M, Schieberle P. 2003. A New LC/MS-Method for the Quantification of 392 Acrylamide Based on a Stable Isolute Dilution Assay and Derivatization with 2393 Mercaptobenzoic Acid. Comparison with Two GC/MS Methods. Journal of $394 \quad$ Agricultural Food Chemistry 51:7866-7871.

395 Mottram DS, Wedzicha BL, Dodson AT. 2002. Food chemistry: Acrylamide is formed 396 in the Maillard reaction. Nature 419:448-449.

397 Nemoto S, Takatsuki S, Sasaki K, Maitani T. 2002. Determination of Acrylamide in 398 Foods by GC/MS Using ${ }^{13}$ C-Labeled Acrylamide as an Internal Standard. Journal of 399 the Food Hygienic Society of Japan 43:371-376.

400 Norwegian Food Control Authority. 2002. Assessement of cancer risk due to 401 acrylamide intake from coffee consumption. Oslo 13 December 2002. Available at 402 http://www.snt.no.

403 Nunes FM, Coimbra MA, Duarte AC, Delgadillo I. 1997. Foamability, foam stability, 404 and chemical composition of espresso coffee as affected by the degree of roast. 405 Journal of Agricultural and Food Chemistry 45:3238-3243. 
406 Nunes FM, Coimbra MA. 1998. Influence of polysaccharide in foam stability of $407 \quad$ espresso coffee. Carbohydrate Polymers 37:283-285.

408 Ono H, Chuda Y, Ohnishi-Kameyama M, Yada H, Ishizaka M, Kobayashi H, Yoshida 409 M. 2003. Analysis of acrylamide by LC-MS/MS and GC-MS in processed Japanese 410 foods. Food Additives and Contaminants 20:215-220.

411 Pittet A, Périsset A, Oberson J-M. 2004. Trace level determination of acrylamide in 412 cereal-based foods by gas chromatography-mass spectrometry. Journal of 413 Chromatography A 1035:123-130.

414 Rosén J, Hellenàs K-E. 2002. Analysis of acrylamide in cooked foods by liquid 415 chromatography tandem mass spectrometry. Analyst 127:880-882.

416 Şenyuva HZ, Gökmen V. 2005. Study of acrylamide in coffee using an improved liquid 417 chromatography mass spectrometry method: Investigation of colour changes and 418 acrylamide formation in coffee during roasting. Food Additives and Contaminants $419 \quad 22: 214-220$.

420 Şenyuva HZ,Gökmen V. 2006. Interference-free determination of acrylamide in potato 421 and cereal-based foods by a laboratory validated liquid chromatography-mass $422 \quad$ spectrometry method. Food Chemistry 97:539-545.

423 Stadler RS, Blank I, Varga N, Robert F, Hau J, Guy PA, Robert M-C, Riediker S. 2002. 424 Acrylamide from Maillard reaction products. Nature 419: 449-450.

425 Svensson K., Abramsson L, Becker W, Glynn A, Hellenas KE, Lind Y, Rosen J. 2003. 426 Dietary intake of acrylamide in Sweden. Food and Chemical Toxicology 41:1581$427 \quad 1586$. 
428 Tareke E, Rydberg P, Karlsson P, Eriksson S, Tornqvist M. 2002. Analysis of 429 Acrylamide, a Carcinogen Formed in Heated Foodstuffs. Journal of Agricultural and $430 \quad$ Food Chemistry 50:4998-5006.

431 Yusà V, Quintás G, Pardo O, Martí P, Pastor A. 2006. Determination of acrylamide in 432 foods by pressurized fluid extraction and liquid chromatography-tandem mass 433 spectrometry used for a survey of Spanish cereal-based foods. Food Additives and 434 Contaminants 23:237-244.

435 Zhang Y, Zhang G, Zhang Y. 2005. Occurrence and analytical methods of acrylamide 436 in heat-treated foods: Review and recent developments. Journal of Chromatography $437 \quad$ A $1075: 1-21$. 


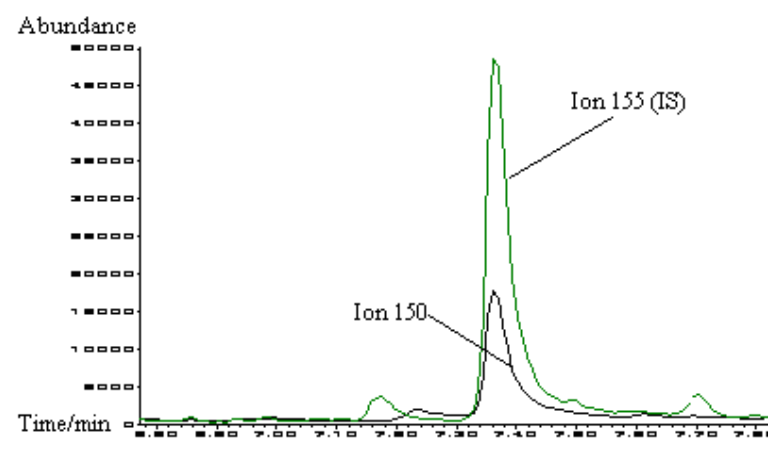

Figure 1. Chromatogram of a ground coffee sample analysed as "espresso" coffee with $20.8 \mu \mathrm{g} \mathrm{L}{ }^{-1}$ AA and addition of $0.5 \mu \mathrm{g}$ of ${ }^{13} \mathrm{C}_{3}$-AA corresponding to a concentration of $50 \mu \mathrm{g} \mathrm{L} \mathrm{L}^{-1} \mathrm{AA} . \mathrm{m} / z .150$ is the quantification ion for $\mathrm{AA}$ and ion $\mathrm{m} / \mathrm{z} 155$ is the quantification ion for ${ }^{13} \mathrm{C}_{3}-\mathrm{AA}$. 
Table I. Acrylamide levels measured in 26 coffee products. The minimum and maximum values are presented and also the mean level of AA in the different coffee products analysed.

\begin{tabular}{cccccccc}
\hline \multirow{2}{*}{ Samples } & \multirow{n}{*}{$\mathrm{n}$} & \multicolumn{3}{c}{ AA found $\mu \mathrm{g} \mathrm{L}^{-1}$} & \multicolumn{3}{c}{$\mu \mathrm{g}$ AA / 30 mL cup } \\
\cline { 3 - 8 } & & Min & Mean & Max & Min & Mean & Max \\
\hline "Espresso" & 18 & 11.4 & 21 & 36.2 & 0.32 & 0.62 & 1.46 \\
Soluble coffee & 5 & 47.4 & 72.4 & 95.2 & 0.47 & 0.72 & 0.95 \\
Coffee blends with cereals & 2 & 200.8 & 215.2 & 229.4 & 2.01 & 2.15 & 2.29 \\
Cappuccino & 1 & - & 6.4 & - & - & 0.45 & - \\
\hline
\end{tabular}

